\title{
Adaptive plasticity during stress and depression and the role of glutamate-nitric oxide
} pathways

\section{BHHarvey}

Division of Pharmacology, School of Pharmacy, North-West University, Potchefstroom, South Africa.

\begin{abstract}
Anxiety and mood disorders are amongst the most prevalent and disabling of all the psychiatric disorders. Under-diagnosis and current treatments that are often less than adequately effective, contributes to an enormous personal and economic cost to the patient, family and health-care organizations. Although distinctly separate disorders at neuropathological and phenomenological levels, brain-imaging studies in posttraumatic stress disorder (PTSD) and depression have emphasized that both illnesses may induce damaging effects on regions of the brain involved in regulating the response to stress. While controversy prevails as to whether these changes represent an adaptive process or are indeed pathological, they are associated with marked changes in memory and other cognitive functions. In depression, a history of prior episodes is correlated with a higher risk of relapse, while poor compliance with antidepressants not only predicts later relapse, it may result in a more rapid shrinkage of the abovementioned brain regions, possibly providing a basis for relapse and treatment resistance. Similarly, even with the introduction of effective medications for PTSD, many patients remain treatment-resistant. Stress in various guises may alter synaptic connectivity in the brain by bolstering glutamatergic excitotoxic mechanisms. Understanding these mechanisms may assist in developing more effective treatment strategies. This paper will review pre-clinical and clinical evidence supporting a role for the glutamatenitric oxide pathway as a putative mediator of the neuropathological changes evident in depression and stress-related disorders, particularly PTSD, and its potential as a novel target for psychotropic activity.
\end{abstract}

Keywords: Depression; PTSD, nitric oxide, glutamate; neuroplasticity; stress

Received: 02.09 .05

Accepted: 28.11 .05

\section{Introduction}

The seminal discovery of the antidepressant imipramine in 1958 and of the mood-stabilising actions of lithium ion in 1949 have set the gold standard for research and treatment in mania and depression. However, since these halcyon days of psychopharmacology, drug discovery has not realized its full potential and in many ways is decades behind our understanding of psychiatric illness. Our newest drugs, for example the serotonin (5HT) reuptake inhibitors (SRI) such as fluoxetine $\left(\right.$ Prozac $\left.^{\circledR}\right)$, are not any more effective than

\section{Correspondence:}

Prof B H Harvey, Division of Pharmacology, School of Pharmacy, North West University, Potchefstroom, 2520, South Africa

email: fklbhh@puk.ac.za imipramine in the treatment of depression ${ }^{1}$ while lithium salts still remain the bench mark treatment for manic depression. ${ }^{2}$ The advent of extremely sophisticated techniques in molecular neuroscience and molecular psychiatry have uncovered a wealth of knowledge pertaining to the development, susceptibility and progression of a psychiatric illness, as well as identifying new candidate target molecules for drug action. However, integrating this into a single working hypothesis upon which drugs can be developed has proved the biggest challenge. Contrary to our early beliefs and hopes in the 1960's, a psychiatric illness is not a single neurotransmitter disorder, but represents a continuum of environmental, genetic and neurochemical determinants that all occupy a variable yet distinct role in the etiology, progression and treatment response of disorders as apparently distinct as depression on one end, to psychosis on 
the other.

Although the monoamine hypothesis of depression has proved to have significant construct validity in that it has formed the basis for the development of our current armamentarium of antidepressant drugs, their delayed onset of action, that they seldom exceed an expected rate of remission of $50 \%{ }^{3}$, and having an unacceptably high incidence of relapse, has paved the way to a more intractable form of the illness. Despite their improved side effect profiles and distinct benefits for long-term outcome due to improved patient compliance, it is becoming increasingly clear that these drugs are not targeting the neurobiological underpinnings of the disorder. While the focus over the past three or more decades has been 5HT, noradrenaline (NA) and dopamine (DA), the rapid advancement of neuroscience has in the past years revealed that brain function is also regulated by many other neurochemicals and neuronal messengers, some acting as transmitters in their own right, while others modify the actions of the more traditional transmitters.

In recent years, increasing evidence has begun to indicate that major depressive disorder, as well as severe stress disorders such as post traumatic stress disorder (PTSD), are associated with neuronal structural remodeling and possibly also neural damage and cell death. ${ }^{4 ; 5}$ Recent brain imaging studies in PTSD patients have highlighted that if not treated aggressively and adequately, the illness may over time induce damaging effects on brain areas important in regulating the stress response, especially the hippocampus. ${ }^{6}$ Thus, multiple exposures to trauma will result in hippocampal shrinkage and cognitive changes, which would appear to be a direct consequence of the illness as both are reversible with effective drug treatment. ${ }^{7}$ Similar structural changes have been observed in depression, including cognitive changes. ${ }^{8: 9}$ As in PTSD, recurrent depressive episodes may act as the driving force for cumulative hippocampal atrophy and possibly permanent damage. . $^{; 10}$

The successful management of both depression and PTSD with the SRI's ${ }^{11 ; 12}$ has increased attention to the role of 5HT in the neurobiology and treatment of stress-related disorders. However, in both instances, these drugs have distinct shortfalls in efficacy.3:12 Many patients therefore have lasting anxiety and other manifestations resulting in chronic psychosocial malfunction with significant socio-economic implications. Improved pharmacotherapeutic interventions are thus urgently needed. While controversy still prevails as to whether the above brain changes are pathological or adaptive ${ }^{13: 14}$, the mechanisms underlying the changes would appear to be a sequel to stress and may present an important target for antidepressant action. ${ }^{15}$ Stress-induced messengers, such as glutamate, that regulate cell excitability and survival are therefore of considerable importance.

\section{Stress: Can't live with it, can't live without it}

The stress response is geared to enhance the probability of survival by promoting the development of coping mechanisms to resist the stressor, and to improve the response to a later similar stressor. Typical responses would include behavioural changes, such as anxiety and aggression, and involuntary actions such as increased heart rate and hormonal changes, eg. adrenaline and cortisol. Stress therefore can be viewed as a challenge that requires behavioral, psychological and physiological adaptation that initiates a series of responses that are vital for survival. This process is referred to as allostasis. However, a balance (homeostasis) is extremely important to ensure harmony between internal regulatory mechanisms and external/ internal stressors. This balance is constantly challenged by repeated physical/psychosocial threats, such that disharmony in allostasis may lead to allostatic load and ultimately a mental illness. ${ }^{16}$

The hypothalamic-pituitary-adrenal (HPA)-axis and the monoaminergic-sympathetic nervous system play an important role in how an animal deals with stress. ${ }^{17}$ Where the catecholamines facilitate the availability of energy to vital organs, glucocorticoids released from the adrenals help to contain the neural responses initiated by the stressor. Allostasis would involve adaptive responses to stress, typically manifested by a short-term activation of the HPAaxis resulting in involuntary response mechanisms, including the mobilisation of energy to the brain and muscles, sharpening/focusing attention on the perceived threat, enhanced heart rate and respiration to improve oxygenation, modulation of the immune response, inhibition of reproductive behavior, decreased feeding and appetite and the laying down of memory related to the event. Allostatic load describes a maladaptive response to the stressor, resulting in over- or under-production of stress hormones and a failure to terminate activation of the HPA-axis. ${ }^{16}$ Under the latter non-physiological conditions, cumulative brain changes take place, described as a process of "wear and tear", that culminate in structural and functional brain changes. The resulting neuropsychiatric dysfunction would be dependent on the severity and duration of the stressor. These structural changes may follow the up-regulation of excitatory pathways that mediate synaptic plasticity, a decrease in cell proliferation and shrinkage of neuronal networks. This deficit in synaptic connectivity lays the foundation for the development of psychiatric illness. ${ }^{15}$

\section{Glutamatergic mechanisms in stress and neuropsychiatric illness}

Without dispelling the important role of catecholamines and indoleamines in the aetiology of affective illness, there is now significant evidence implicating excitatory N-methyl-Daspartate (NMDA)-glutamate and inhibitory gamma amino butyric acid (GABA) pathways in depression ${ }^{18 ; 19}$ and PTSD. 20;21 Glutamatergic NMDA pathways play an important role in neural plasticity and modifying existing neural

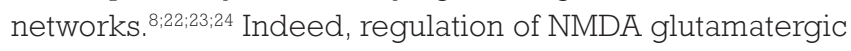
mechanisms is implicated in both the behavioral and adaptive neuronal response to antidepressants and may have a key role in both the neuropathology and treatment of affective illness. ${ }^{15 ; 25} \mathrm{GABA}$ occupies a critical role in inhibiting glutamatergic transmission via pre-synaptic GABA-B heteroreceptors ${ }^{26}$, such that stress-induced GABA release in the hippocampus may play an important protective mechanism to curb excessive glutamate activation. ${ }^{20}$

The nitric oxide (NO)-pathway In the central nervous system (CNS), glutamate activation of the NMDA receptor mediates the release of the pleiotropic messenger molecule, $\mathrm{NO}$, via activation of the $\mathrm{Ca}^{2+}$ - 
dependent neuronal NO synthase (nNOS) (Figure l) ${ }^{27}$ Constitutive nNOS and endothelial (eNOS) produce receptorregulated pulses of $\mathrm{NO}$, while the inducible (iNOS) enzyme in macrophages and microglia produces sustained levels of $\mathrm{NO}$ in response to cytokines. Inducible NOS is primarily involved in inflammatory reactions, producing sustained cytotoxic concentrations of NO. Receptor-regulated NO release has important neuroregulatory properties in the cardiovascular system (via eNOS), while in the CNS (via nNOS), NO is implicated in a variety of higher functions, including learning, memory, and emotionality. ${ }^{23: 27}$ In the context of this paper, it is the neurotoxic actions of $\mathrm{NO}^{27}$ as well as its effects on 5HT, $\mathrm{NA}, \mathrm{DA}$ and acetylcholine release $\mathrm{e}^{27 ; 28 ; 29}$ that are especially important.

NO is a small gaseous, paramagnetic molecule with great lipid solubility. These properties allow it to rapidly move within and between cells where it binds to and stimulates the soluble guanylate cyclase leading to an increase in the second messenger, cyclic guanosine monophosphate (cGMP; Figure 1). ${ }^{28}$ Important neuronal effects of cGMP include activation of $\mathrm{G}$-kinase, activation or inhibition of phosphodiesterase (PDE) and subsequent effects on cyclic adenosine monophosphate (CAMP), effects on ion channels and G-proteins and neurotransmitter release. ${ }^{29}$ All these actions exert a significant effect on neuronal function. The effects of cGMP are terminated by the PDE family, among which PDE 3 and PDE 5 are considered specific for CGMP. ${ }^{30}$

High concentrations of NOS are found in brain regions involved in the modulation of anxiety and defensive behaviour. ${ }^{31}$ Exposure to stressful stimuli has been found to induce the activation of NO-producing neurons in the amygdala, hypothalamus, peri-aquaductal grey, and

Figure 1: The glutamate-NMDA receptor mediated activation of the NO-cGMP pathway in the CNS. Upon binding of glutamate (Glu) to the NMDA receptor, the resulting influx of $\mathrm{Ca}^{2+}$ leads to the activation of nNOS in a calmodulin (Calm) -dependent manner and the synthesis of NO from L-arginine (L-arg). NO then binds to and activates soluble guanylate cyclase (sGC) leading to the synthesis of cGMP that is responsible for cell-specific responses. NO is broken down to nitrogen oxides $\left(\mathrm{NO}_{2}-\right.$ and $\left.\mathrm{NO}_{3}^{-}\right)$, with the actions of $\mathrm{CGMP}$ terminated by type-5 phosphodiesterase (PDE-V). Another source of NOS activation indicated in the sketch is via $\mathrm{Ca}^{2+}$ release from the endoplasmic reticulum (ER) via metabotropic receptor induced activation of phospholipase (PLC) and the synthesis of inositol triphosphate (IP from the membrane lipid, phosphatidylinositol bisphosphate (PIP $\left.{ }_{2}\right)$. Excessive release of NO, following overt NMDA receptor activation, leads to non-specific binding of NO to especially other iron-containing cellular proteins with neurotoxic consequences.

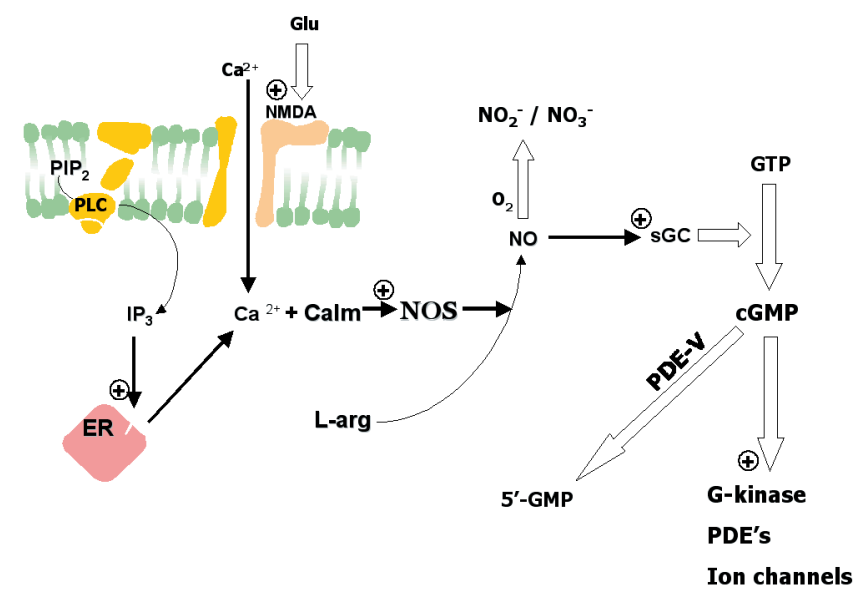

pedunculopontine tegmental nucleus. ${ }^{32}$ Although NO normally acts to conserve neural function, under conditions of allostatic load and increased glutamate-NOS activity, excessive release of NO will react with many cellular proteins resulting in neuronal damage or death. ${ }^{27}$ Thus, targetting glutamate and NO may play an important role in treating anxiety-related behaviors. Indeed, drugs acting at various targets within the NMDA-NO pathway, including guanylate cyclase inhibitors ${ }^{33 ; 34}$, NMDA receptor antagonist $\mathrm{s}^{35}$, and NOS inhibitors ${ }^{36}$ all demonstrate significant anxiolytic properties in animal models of anxiety, while increasing cGMP in the brain with the selective PDE-5 inhibitor, sildenafil, causes anxiogenic effects. $37 ; 38$

\section{Depression, antidepressant compliance and nitric oxide}

Major depression is a mood disorder that invariably follows chronic environmental adversity and stress. ${ }^{39}$ Ordinarily the body will initiate adaptive mechanisms to cope with psychosocial stressors, as described earlier. However, depending on the susceptibility of the person, i.e. genetic predisposition, and the nature and duration of the stressor, these coping mechanisms may become over-whelmed leading to a maladaptive response, structural brain changes and the gradual development of depressive behavior. Typical neuroendocrine changes include an increased circulating cortiso $^{14}$ and variable monoamine changes, one being the gradual depletion of synaptic monoamines, and up-regulation of monoamine receptors due to a maladaptive over-use, in keeping with the monoamine hypothesis of depression. ${ }^{1140}$

Studies in rats, however, have shown that structural and damaging brain changes appear only after extreme chronic stress. ${ }^{14}$ This has not been supported by clinical and experimental observations in humans, although post-mortem studies in depressives show adaptive and reversible changes in structural parameters in the hippocampus after stress. ${ }^{14}$ Thus, while the HPA-axis in depression is moderately activated, possibly due to the initial (primary) hippocampal degeneration in this condition, the ensuing structural changes are likely to be adaptive in nature. Nevertheless, cortisol still plays an important role in the symptoms of depression, but may also have more insidious effects by evoking the release of glutamate. . $^{841}$

Evidence from imaging studies would concur that recurrent depressive episodes appear to be a driving force for cumulative hippocampal atrophy. ${ }^{9: 10}$ Patients with depression and anxiety disorders all too often discontinue antidepressants prematurely ${ }^{42}$, while patients discontinuing antidepressants have a 2 to 4 times greater risk of relapse than those maintained on medication. ${ }^{43}$ Similarly, greater number and longer duration of episodes of depression are associated with a higher risk of later relapse and recurrence. ${ }^{44 ; 45}$ While corroborating clinical data are difficult to generate for ethical reasons, inappropriate antidepressant discontinuation may prove to be a driving force that prompts subsequent episodes that are of longer duration, more severe and less treatment-responsive.

Chronic stress is recognized as one of the most important initiators of the cellular events that pre-date the development of depression and its associated neuropathology. ${ }^{39}$ Antidepressant withdrawal is associated with increased stress 
system activity involving the hypothalamic-pituitary growth axis and the sympathetic nervous system. ${ }^{46}$ Precious little is known of the neurobiological mechanisms that are activated following antidepressant withdrawal, and of their implications for the course and prognosis of depression. However, patients with a history of switching are associated with a more rapid decline in hippocampal volume ${ }^{9}$, suggesting that inappropriate antidepressant discontinuation may hasten adaptive plasticity and so be detrimental to long-term outcome.

The ability of both humans and animals to exert control over their environment is dependent on "coping behavior" that prevents the deleterious effects of stress. This represents an important homeostatic mechanism against the development of depression. Thus, animals subjected to an inescapable stressor, such as forced swim stress, will demonstrate increased immobility once they perceive a lack of control over the situational stressor. This represents a state of "learned helplessness" or "behavioural despair" in which active coping mechanisms are eventually attenuated. Effective antidepressants counter the "stress-induced" immobility response. In clinical depression, this trait is evident in symptoms such as decreased volition (drive), apathy, lack of self-worth and esteem and locomotor retardation.

Using swim stress as an unconditioned situational stressor, acute imipramine withdrawal after chronic treatment has been found to evoke an increase in stress responsiveness. That this response is associated with an increase in hippocampal glutamate NMDA receptor density, while both behavioral and receptor changes are reversible with an NMDA receptor antagonist ${ }^{47}$, is of significant importance. Antidepressant withdrawal, therefore, increases the number of NMDA receptors with an increased probability of receptor binding by available synaptic glutamate. Since major depressive illness may be associated with increased circulating glutamate levels ${ }^{48: 49}$, while antidepressant response involves a dampening of NMDA receptor function ${ }^{25 ; 4750}$, the increase in NMDA receptor density described after antidepressant withdrawal reflects a primary increase in glutamatergic tone subsequent to removal of the inhibitory effect of the antidepressant. Imipramine withdrawal associated stress also engenders a significant increase in hippocampal NOS activity, confirming that antidepressant discontinuation increases stress responsiveness together with disinhibition of hippocampal NOS. ${ }^{51}$ The resulting increased glutamate and nitrergic activity may have significant implications for depressive illness and its treatment ${ }^{29 ; 41}$, possibly via a damaging effect on neurons, or by altering 5HT and NA release. ${ }^{27}$

Pre-clinical studies have confirmed the antidepressantlike properties of NOS inhibitors ${ }^{52}$ while various clinically effective antidepressants inhibit NOS. ${ }^{53}$ Of special note is that NMDA antagonists and NOS inhibitors can augment the antidepressant action of typical antidepressants ${ }^{54 ; 55}$ suggesting that the less than adequate efficacy of current antidepressant in treating depression may be due to a relative shortfall in NMDA-NOS activity. Unfortunately, selective NOS inhibitors are unsuitable for clinical use but it is of interest that these compounds elicit antidepressant-like activity through a 5HT dependent mechanism ${ }^{56}$, effectively relating actions on NOS to the 5HT hypothesis of depression.
The characteristic physical and psychological symptoms of antidepressant withdrawal, including dizziness, nausea, gastrointestinal distress, headache, anxiety and gait instability ${ }^{57: 58}$ are typical symptoms associated with increased serotonergic activity. ${ }^{59}$ Excessive 5HT activity may therefore drive both the behavioral as well as neurochemical changes following antidepressant withdrawal. Indeed, concomitant administration of a $5 \mathrm{HT}_{2 \mathrm{~A} / \mathrm{C}}$ receptor antagonist prevents imipramine withdrawal associated stressresponsiveness and NOS hyper-function ${ }^{51}$, suggesting that increased NOS activity post-withdrawal is mediated through a mechanism involving $5 \mathrm{HT}_{2 \mathrm{~A} / \mathrm{C}}$ receptor activation. This is of considerable relevance not only because of the important role for 5HT in depressive symptomology, but concurs with earlier studies that raised synaptic 5HT levels may be detrimental to neuronal function and integrity. ${ }^{60}$ Indeed, 5-HT released during stress may contribute to neuroplastic events by enhancing NMDA receptor efficacy. ${ }^{22 ; 61}$ Thus, antidepressant withdrawal not only evokes troublesome side effects via increased 5HT activity that are ultimately selflimiting, but through neuronal release of NO more insidious long-term complications may be realized that may underlie structural brain changes evident in brain imaging studies in depression, as well as manifest as treatment resistance and repeated relapse.

In agreement with a role for glutamate in depression, post-mortem studies have found changes in the NMDA receptor complex in the frontal cortex ${ }^{62}$, and reduced NMDA receptor expression in the hippocampus of depressives. ${ }^{63}$ Platelet glutamate receptor super-sensitivity is also evident in patients with depression ${ }^{64}$, while NMDA receptor antagonists, such as amantadine and ketamine, have been found to be remarkably effective in severe, treatment resistant depression. ${ }^{25 ; 65}$ Recent clinical studies have also confirmed altered activity of the NO pathway in depression ${ }^{66 ; 67}$, as well as bipolar affective disorder ${ }^{68 ; 69}$, while lithium too has distinct activity on the NO pathway. ${ }^{70 ; 11}$ These data suggest that alternate disturbances in mood, as well as anti-manic and antidepressant drugs of various classes modulate the NOpathway.

\section{PTSD and the role of nitric oxide}

PTSD is a severely disabling anxiety disorder that may occur following exposure to an acute traumatic event. ${ }^{72}$ The disorder is characterized by re-experiencing and hyperarousal symptoms, as well as by avoidance symptoms and problems with explicit recall of memories. Re-experiencing symptoms include intrusive recollections of the original trauma in the form of recurrent daytime memories, nightmares and flashbacks. Avoidance and amnesic symptoms include "feeling numb" and gaps in memory that may last from minutes, hours, even days.

While the mediating role of glucocorticoids, particularly cortisol, in the psychobiology of PTSD is well-recognised ${ }^{73 ; 74}$, clinical studies on HPA-axis activity during PTSD have been inconsistent. ${ }^{75}$ The evidence for a hyper-responsivity of the negative feedback inhibition of cortisol on glucocorticoid receptors in the HPA-axis resulting in hypocortisolemia ${ }^{76}$ suggest that individuals who develop PTSD respond to a traumatic event by failing to release sufficient levels of cortisol for a long-enough period of time to shut down stress- 
induced sympathetic nervous system responses. ${ }^{77}$ This lack of HPA axis control over the stress response may be a consequence of hippocampal damage/atrophy in the acute period post stress. Circulating glucocorticoids exert a bidirectional effect on hippocampal function, eg memory, such that while hippocampal damage may be associated with exposure to excessive levels of glucocorticoids, too low levels post stress are also detrimental for normal hippocampal function. ${ }^{78}$ The incidence and severity of PTSD is dependent on multiple exposures to trauma ${ }^{79}$ that is compounded by hippocampal damage, a perpetuating stress-response and a dysfunction in memory formation. These are evinced by hypo- or hypercortisolemia, re-experiencing of trauma memories and attenuation of explicit memory function.

Although there is evidence of decreased hippocampal volume predating PTSD ${ }^{80}$, the hypothesis that PTSD leads to hippocampal atrophy and associated memory deficits is supported by both clinical ${ }^{7}$ and pre-clinical research ${ }^{84 ; 85}$ where associated memory changes (and decreased hippocampal volume in patients) in PTSD and in animals can be reversed with SRI's. Associative learning and other behavioral processes mediated by the hippocampus and that play a role in PTSD, involve glutamate NMDA receptors. ${ }^{81}$ Dysfunctional brain glutamatergic systems, particular the NMDA receptor, have been suggested as an important neurobiological component of PTSD, perhaps contributing to adaptive hippocampal changes. ${ }^{21}$ Animal studies implicate the hippocampus in emotional processing as well as explicit memory ${ }^{82}$, where stress-related hippocampal structural changes appear related to the neurotoxic effects of glucocorticoids and the subsequent release of glutamate $e^{8 ; 24}$, thus implicating a possible role for down-stream messengers of the NMDA receptor.

Inducible $\mathrm{NOS}^{83}$ and $\mathrm{nNOS}^{84}$ has been found to be activated following acute severe stress in rats. Using timedependent sensitization (TDS) stress, a putative animal model of PTSD ${ }^{85 ; 86}$, we have found that repeated trauma causes a sustained elevation in iNOS-mediated NO synthesis in the hippocampus. ${ }^{87}$ That stress-induced NO release is inhibited by ketoconazole, a steroid synthesis inhibitor, further confirms the role of stress-induced glucocorticoids in this response. ${ }^{87}$ iNOS is activated by cytokines ${ }^{27}$, pivotal modulators of inflammatory processes. ${ }^{88}$ Psychological stress in humans is associated with increased secretion of proinflammatory cytokines, such as interleukin- $6^{89}$, and high levels of cerebrospinal fluid interleukin-6 have been measured in patients with PTSD. ${ }^{90}$ Since interleukin-6 secretion is suppressed by glucocorticoids ${ }^{90}$, conditions of hypocortisolemia as often noted in PTSD may allow an unopposed increase in interleukin-6 secretion, with subsequent increase in iNOS activation. These data make the startling suggestion that PTSD may be an inflammatory disease ${ }^{20}$, possibly underlying the structural changes that have been noted in the disorder.

TDS stress has also been found to significantly increase the accumulation of hippocampal NOx, the stable oxidative metabolite of $\mathrm{NO} .{ }^{91}$ Of note is that this response can be blocked by an nNOS inhibitor or an inhibitor of nuclear factor kappa beta (NFא- $\beta$ ), an important transcription factor mediating the induction of iNOS. Interestingly, the glutamate NMDA receptor antagonist, memantine was found to be ineffective, possibly due to a down-regulated state of the NMDA receptors following stress. ${ }^{86}$ The cGMP-specific PDE inhibitor, sildenafil, however, significantly augmented stressinduced NOx accumulation. ${ }^{91}$ These data conclude that increasing neuronal cGMP acts as a protagonist in driving stress-related events, while both nNOS and iNOS may represent a therapeutic target in preventing the effects of severe stress. While the value of NMDA receptor antagonism appears limited, targeting its sub-cellular linkage to the NOcGMP pathway may have important implications for the pharmacological treatment of PTSD.

It is noteworthy that a recent clinical study has described the involvement of the NO-pathway in patients with acute PTSD $^{92}$, while the drugs of choice in the treatment of PTSD, the SRI's $^{7,12}$, have been found to inhibit hippocampal NOS. ${ }^{53}$ Moreover, D-cycloserine, a partial agonist at the glycine regulatory site on the NMDA receptor has demonstrated clinical efficacy in treating PTSD. ${ }^{93}$ These studies provide a strong rationale that the NMDA receptor and its down-stream events represent an important pharmacological and therapeutic target for the treatment of PTSD.

\section{Conclusion}

Anxiety disorders are the most prevalent, disabling and chronic of psychiatric disorders ${ }^{94 ; 95}$ and their undertreatment contributes to enormous personal and economic costs. ${ }^{9697}$ In particular, mood and stress-related disorders are becoming a growing global health burden, while current treatments are in most cases less than adequately effective. This paper has only discussed the CNS role of NO in depression and stress. However, NO occupies an extremely important regulatory role in the cardiovascular system and, considering the long-term detrimental effect of stress on this system, it is well worth making mention of an important point in this regard. Stressing rats is associated with an increase in atrial sensitivity to circulating catecholamines. ${ }^{98}$ More interesting, however, is that NMDA receptor blockade may prevent stress-induced cardiotoxicity ${ }^{99}$, suggesting that glutamatergic pathways are mobilized during severe stress and may also be driving the peripheral autonomic manifestations of stress. Clearly, understanding the mediating psychobiology of these disorders will assist in developing effective interventions, while such advances can be drawn upon to encourage early detection and effective treatment of the anxiety disorders. ${ }^{100}$

Despite early advances in the drug treatment of depression and anxiety some 50 years ago, and more recent developments that have identified new putative neurobiological targets in depression and PTSD, the currently available drugs are disappointing in their long-term efficacy. While targeting monoamine transmission has been successful, this has only been partially so and one is left with the question whether we are targeting the correct processes with our drugs. Moreover, are these "less than effective" drugs maybe worsening the illness through incorrect usage, leading to the escalating relapse rates and chronic morbidity associated with these disorders? New targets for drug treatment, and novel ideas for psychotropic drug design are urgently needed and this paper has highlighted at least one potentially useful avenue of investigation, viz. the glutamate-NO-pathway. 


\section{Acknowledgements}

This paper is based on an inaugural lecture by the author delivered at North-West University in May 2005. This work has been supported by the South African Medical Research Council (MRC) and the National Research Foundation (NRF grant number 2053203)

\section{References}

1. Geddes JR, Freemantle N, Mason J, Eccles MP, Boynton J. SSRIS versus other antidepressants for depressive disorder. Cochrane Database Syst Rev 2000; (2): CD001851

2. Compton MT, Nemeroff CB. The treatment of bipolar depression. $J$ Clin Psychiatry 2000; 61 suppl 9: 57-67.

3. Kocsis JH. Pharmacotherapy for chronic depression. J Clin Psychol 2003; 59: 885-892

4. Rajkowska G. Postmortem studies in mood disorders indicate altered numbers of neurons and glial cells. Biol Psychiatry 2000; 48 766-777.

5. D'Sa C, Duman RS. Antidepressants and neuroplasticity. Bipolar Disorders 2002; 4: 184-194.

6. Elzinga BM, Bremner JD. Are the neural substrates of memory the final common pathway in posttraumatic stress disorder (PTSD)? J Affective Dis 2002; 70: 1-17.

7. Vermetten E, Vythilingam M, Southwick SM, Charney DS, Bremner JD. Long-term treatment with paroxetine increases verbal declarative memory and hippocampal volume in posttraumatic stress disorder. Biol Psychiatry 2003; 54: 693-702

8. McEwen BS. Stress and hippocampal plasticity. Annu Rev Neurosci 1999; 22: 105-122

9. MacQueen GM, Campbell S, McEwen BS, MacDonald K, Amano S, Joffe RT, Nahmias C, Young LT. Course of illness, hippocampal function, and hippocampal volume in major depression. Proc Natl Acad Sci USA 2003; 100: 1387-1392.

10. Sheline Y, Sanghavi M, Mintun M, Gado M. Depression duration but not age predicts hippocampal volume loss in medical healthy women with recurrent major depression. J Neuroscience 1999; 19 : 5034-5043.

11. Harvey BH. The neurobiology and pharmacology of depression: a comparative overview of the serotonin-selective antidepressants. S Afr Med J 1997; 87: 540-552

12. Stein DJ, Zungu-Dirwayi N, van Der Linden GJ, Seedat S. Pharmacotherapy for posttraumatic stress disorder. Coch Datab Syst Rev 2000; 4: CD002795.

13. Gilbertson MW, Shenton ME, Ciszewski A, et al. Smaller hippocampal volume predicts pathologic vulnerability to psychological trauma. Nature Neurosci 2002; 5: 1242-1247

14. Swaab DF, Bao AM, Lucassen PJ. The stress system in the human brain in depression and neurodegenration. Age Res Rev 2005; [Epub ahead of print].

15. Malberg JE, Schechter LE. Increasing hippocampal neurogenesis: a novel mechanisms for antidepressant drugs. Curr Pharm Des 2005; 11: 145-155.

16. McEwen BS. Protection and damage from acute and chronic stress: allostasis and allostatic overload and relevance to the pathophysiology of psychiatric disorders. Annal NY Acad Sci 2004; 1032: 1-7

17. Heuser I, Lammers CL. Stress and the brain. Neurobiol Aging, 2003:24: S69-S76.

18. Shiah IS, Yatham LS. GABA function in mood disorders: An update and critical evidence. Life Sci 1998; 63:1289-1303

19. Kendell SF, Krystal JH, Sanacora G. GABA and glutamate systems as therapeutic targets in depression and mood disorders. Expert Opin Ther Targets 2005; 9: 153-168.

20. Oosthuizen F, Wegener G, Harvey BH. Role of nitric oxide as inflammatory mediator in post-traumatic stress disorder (PTSD): Evidence from an animal model. Neuropsych Dis Treat 2005; 1: 109124.

21. Chambers RA, Bremner JD, Moghaddam B, Southwick SM et al. Glutamate and post-traumatic stress disorder: Towards a psychobiology of dissociation. Semin Clin Neuropsychiatry 1999; 4: 274-281.

22. McEwen BS, Conrad CD, Kuroda Y, Frankfurt $M$ et al. Prevention of stress-induced morphological and cognitive consequences. Eur Neuropsychopharmacol 1997; 7: 323-328.

23. McLeod TM, Lopez-Figueroa AL, Lopez-Figueroa MO. Nitric oxide, stress, and depression. Psychopharmacol Bull 2001; 35: 24-41.

24. Sapolsky RM. Glucocorticoids and hippocampal atrophy in neuropsychiatric disorders. Arch Gen Psychiatry 2000; 57: 925-935.

25. Skolnick P. Antidepressants for the new millenium. Eur J Pharmacol 1999; 375: 31-40.

26. Yamada J, Saitow F, Satake S, Kiyohara T, Konoshi S. GABA $A_{B}$ receptormediated presynaptic inhibition of glutamatergic and GABA'ergic transmission in the basolateral amygdala. Neuropharmacology 1999; 38: 1743-1753.

27. Dawson VL, Dawson TM. Physiological and toxicological actions of nitric oxide in the central nervous system. In Ignarro $L$ and Murad F. Volume eds. Nitric oxide: biochemistry, molecular biology, and therapeutic implications. London: Academic Press 1995;323-330.

28. Prast H, Philippu A. Nitric oxide as modulator of neuronal function. Prog Neurobiol 2001; 64: 51-68.

29. Harvey BH. Affective disorders and nitric oxide: A role in pathways to relapse and refractoriness. Human Psychopharmacology 1996; 11: 309-319

30. Soderling SH, Beavo JA. Regulation of CAMP and CGMP signaling: New phosphodiesterases and new functions. Curr Opin Cell Biol 2000; 12:174-9

31. Vincent SR, Kimura H. Histochemical mapping of nitric oxide synthase in the rat brain. Neurosci 1992; 46: 755-784.

32. Krukoff TL, Khalili P. Stress-induced activation of nitric oxideproducing neurons in the rat brain. J Comp Neurol 1997; 377: 509519.

33. Eroglu L, Caglayan B. Anxiolytic and antidepressant properties of methylene blue in animal models. Pharmacol Res 1997; 36: 381-385.

34. Heiberg $I L$, Wegener G, Rosenberg R. Reduction of CGMP and nitric oxide has antidepressant-like effects in the forced swimming test in rats. Behav Brain Res 2002; 134: 479-484.

35. Padovan CM, Del Bel EA, Guimaraes FS. Behavioral effects in the elevated plus maze of an NMDA antagonist injected into the dorsal hippocampus: influence of restraint stress. Pharmacol Biochem Behav 2000; 67: 325-30.

36. Volke $V$, Wegener $G$, Bourin $M$ et al. Antidepressant- and anxiolyticlike effects of selective neuronal NOS inhibitor 1-(2trifluoromethylphenyl)-imidazole (TRIM) in mice. Behav Brain Res 2003a;140:141-147.

37. Volke V, Wegener G, Vasar E. Augmentation of the NO-cGMP cascade induces anxiogenic-like effect in mice.J Physiol Pharmacol 2003b; 54: 653-60

38. Kurt M, Bilge SS, Aksoz E, Kukula O, Celik S, Kesim Y. Effect of sildenafil on anxiety in the plus-maze test in mice. Pol $J$ Pharmacology 2004; 56: 353-357.

39. Van Praag HM. Can stress cause depression? Prog Neuropsychopharmacol Biol Psychiatry 2004; 28: 891-907. 
40. Leonard BE. Fundamentals of Psychopharmacology, 3rd ed. John Wiley and Sons, Chichester, UK, 2003.

41. Harvey BH, MCEwen BS, Stein DJ . Neurobiology of antidepressant withdrawal: Implications for the longitudinal outcome of depression. Biol Psychiatry 2003a; 54: 1105-1117.

42. Basco MR, Rush AJ. Compliance of pharmacotherapy in mood disorder. Psychiatr Ann 1995; 25: 269-279.

43. Nierenberg $A$ A. Long-term management of chronic depression. J Clin Psychiatry 2002; 62 S6:17-21

44. Judd LL, Akiskal HS, Maser JD, Zeller PJ et al. Major depressive disorder: a prospective study of residual subthreshold depressive symptoms as predictor of rapid relapse. J Affect Disord 1998; 50: 97 108.

45. Keller MB, Boland RJ. Implications of failing to achieve successful long-term maintenance treatment of recurrent unipolar major depression. Biol Psychiatry 1998; 44: 348-360.

46. Michelson D, Amsterdam J, Apter J, Fava M et al. Hormonal markers of stress response following interruption of selective serotonin reupake inhibitor treatment. Psychoneuroendocrinology 2000; 25. 169-177.

47. Harvey BH, Jonker LP, Brand L, Heenop M, Stein DJ. NMDA receptor involvement in imipramine withdrawal-associated effects on swim stress, GABA levels and NMDA receptor binding in rat hippocampus. Life Sci 2002;71: 45-57.

48. Altamura C, Maes M, Dai J, Meltzer HY. Plasma concentrations of excitatory amino acids, serine, glycine, taurine and histidine in major depression. Eur Neuropsychopharmacol 1995; 5 suppl : 71 75.

49. Mauri MC, Ferrara A, Boscati L, Bravin S et al. Plasma and platelet amino acid concentrations in patients affected by major depression and under fluvoxamine treatment. Neuropsychobiology 1998; 37: 124-129

50. Boyer PA, Skolnick P, Fossum LH. Chronic administration of imipramine and citalopram alters the expression of NMDA receptor subunit mRNA's in mouse brain. J Mol Neuro SCi 1998; 10 : 21 9-233.

51. Harvey BH, Retief R, Nel A, Wegener G. Increased hippocampal NO synthase activity and stress responsiveness after imipramine discontinuation: Role of $5 \mathrm{HT}_{2 \mathrm{Z} / \mathrm{C}}$ receptors. Met Brain Dis (in press).

52. Harkin AJ, Bruce KH, Craft B, Paul IA. Nitric oxide synthase inhibitors have antidepressant-like properties in mice. 1. Acute treatments are active in the forced swim test. Eur J Pharmacol 1999;372: 207-13.

53. Wegener G, Volke V, Harvey BH, Rosenberg R. Local, but not systemic, administration of serotonergic antidepressants decreases hippocampal nitric oxide synthase activity. Brain Res2003' 959: 128134.

54. Rogó_Z, Skuza G, Maj J, Danysz W. Synergistic effects of uncompetitive NMDA receptor antagonists and antidepressant drugs in the forced swimming test in rats. Neuropharmacology 2002;42: 1024-1030.

55. Harkin A, Connor TJ, Burns MP, Kelly JP. Nitric oxide synthase inhibitors augment the effects of serotonin re-uptake inhibitors in the forced swimming test. Eur Neuropsychopharmacol 2004; 14: 274-81.

56. Harkin A, Connor TJ, Walsh M, St John N, Kelly JP. Serotonergic mediation of the antidepressant-like effects of nitric oxide synthase inhibitors. Neuropharmacology 2003; 44: 616-23.

57. Schatzberg AF, Haddad P, Kaplan EM, Lejoyeux M et al. Possible biological mechanisms of the serotonin reuptake inhibitor discontinu ation syndrome. J Clin Psychiatry 1997; 58 S7: 23-27.

58. Zajecka J, Tracey KA, Mitchell S. Discontinuation symptoms after treatment with serotonin reuptake inhibitors: a literature review. J
Clin Psychiatry2002; 58: 291-297

59. Coupland NJ, Bell CJ, Potokar JP. Serotonin reuptake inhibitor withdrawal. J Clin Psychopharmacol 1996;1 16: 356-362.

60. Vaidya VA, Rewilliger RMZ, Duman RS. Role of 5HT2A receptors in the stress-induced down-regulation of brain-derived neurotrophic factor expression in rat hippocampus. Neurosci Lett 1999;262: 1-4.

61. McEwen BS. Possible mechanisms for atrophy of the human hippocampus. Mol Psychiatry 1997; 2: 255-262.

62. Nowak G, Ordway GA, Paul IA. Alterations in the N-methyl-Daspartate (NMDA) receptor complex in the frontal cortex of suicide victims. Brain Res1 995; 675: 157-164.

63. Law AJ, Deakin JF. Asymmetrical reductions of hippocampal NMDARI glutamate receptor mRNA in the psychoses. Neuroreport 2001; 12: 2971-2974.

64. Berk M, Plein H, Ferreira D. Platelet glutamate receptor supersensitivity in major depressive disorder. Clin Neuropharmacol 2001;24: 129-132.

65. Stryjer R, Strous RD, Shaked G, Bar F, Feldman B, Kotler M, Pola Rosenzcwaig S, Weizman A. Amantadine as augmentation therapy in the management of treatment resistant depression. Int Clin Psychopharmacol 2003;18: 93-96.

66. Suzuki E, Yagi G, Nakaki T et al. Elevated plasma nitrate levels in depressive states. J Affect Disord 2001; 63: 221-224.

67. Xing G, Chavko M, Zhang LX, Yang S, Post RM. Decreased calciumdependent constitutive nitric oxide synthase (CNOS) activity in prefrontal cortex in schizophrenia and depression. Schizophrenia Res 2002; 58: 21-30

68. Yanik M, Vural H, Tutkun H, Zoroglu SS, Savas HA, Herken H, Kocyigit A, Keles $H$, Akyol O. The role of the arginine-nitric oxide pathway in the pathogenesis of bipolar affective disorder. Eur Arch Psychiatry Clin Neurosci 2004 254: 43-7.

69. Reif A, Strobel A, Jacob CP, Herterich S, Freitag CM, Topner T, Mossner R, Fritzen S, Schmitt A, Lesch KP. A NOS-III haplotype that includes functional polymorphisms is associated with bipolar disorder. Int J Neuropsychopharmacol 2005; 21:1-8

70. Harvey BH, Carstens ME, Taljaard JJF. Evidence that lithium induces a glutamatergic:nitric oxide - mediated response in rat brain. Neurochemical Research 1994; 19: 469-474.

71. Maruta S, Suzuki E, Yokoyama M, Sato T, Inada K, Watanabe S, Miyaoka H. Effects of intraperitoneally injected lithium, imipramine and diazepam on nitrate levels in rat amygdala. Psychiatry Clin Neurosci 2005;59: 358-61.

72. American Psychiatric Association: Diagnostic and Statistical Manual of Mental Disorders, 4th Edition, APA, Washington, DC, USA, 1994.

73. Schelling G, Kilger E, Roozendaal B, de Quervain DJF et al. Stress doses of hydrocortisone, traumatic memories, and symptoms of posttraumatic stress disorder in patients after cardiac surgery: a randomized study. Biol Psychiatry 2004; 55: 627-633.

74. Raison CL, Miller AH. When not enough is too much: the role of insufficient glucocorticoid signaling in the pathophysiology of stress-related disorders. Am J Psychiatry 2003; 160: 1554-65.

75. Rasmusson AM, Vythilingam M, Morgan CA 3rd. The neuroendocrinology of posttraumatic stress disorder: new directions. CNS Spectr 2003; 8: 651-657.

76. Yehuda R, Bierer LM, Schmeidler J, Aferiat DH, Breslau I, Dolan S. Low cortisol and risk for PTSD in adult offspring Holocaust survivors. Am J Psychiatry 2000; 157: 1252-1259.

77. Yehuda R, Harvey H. Relevance of neuroendocrine alterations in PTSD to cognitive impairments of trauma survivors. In: Read D, Lindsay S (eds.). Recollections of Trauma: Scientific Research and Clinical Practice. New York: Plenum Press 1997; 221-252. 
78. De Kloet ER, Oitzl MS, Joels M. Stress and cognition: are corticosteroids good or bad guys? Trends Neurosci 1999; 22: 422-6.

79. Maes M, Mylle J, Delmeire L, Janca A. Pre- and post-disaster negative life events in relation to the incidence and severity of posttraumatic stress disorder. Psychiatry Res 2001; 105: 1-12.

80. Pitman RK, Shin LM, Rauch SL. Investigating the pathogenesis of post-traumatic stress disorder with neuroimaging. J Clin Psychiatry 2001; 62 suppl 17: 47-54.

81. Heresco-Levy U, Javitt DC. The role of $N$-methyl-D-aspartate (NMDA) receptor-mediated neurotransmission in the pathophysiology and therapeutics of psychiatric syndromes. Eur Neuropsychopharmacol 1998; 8: 141-152.

82. Brown ES, Rush AJ, McEwen BS. Hippocampal remodeling and damage by corticosteroids: implications for mood disorders. Neuropsychopharmacology 1999; 21: 474-484.

83. Madrigal JLM, Moro MA, Lizasoain I et al. Inducible nitric oxide synthase expression in brain cortex after acute restraint stress is regulated by nuclear factor kappaB-mediated mechanisms. Journal of Neurochemistry 2001; 76: 532-538.

84. De Oliviera RM, Aparecida Del Bel E, Mamede-Rosa ML, Padovan CM, Deakin JF, Guimaraes FS. Expression of neuronal nitric oxide synthase $m R N A$ in stress-related brain areas after restraint in rats. Neuroscience Letters2000; 289: 123-126.

85. Harvey BH, Naciti C, Brand L, Stein DJ. Endocrine, cognitive and hippocampal-cortical $5 H_{1 \mathrm{~A}-2 \mathrm{~A}}$ receptor changes evoked by a timedependent sensitization (TDS) stress model in rats. Brain Res2003b; 983: 97-107.

86. Harvey BH, Naciti C, Brand L, Stein DJ. Serotonin and stress: Protective or malevolent actions in the biobehavioural response to repeated trauma. Annal NY Acad Sci 2004a; 1032: 267-272.

87. Harvey BH, Oosthuizen F, Brand, Wegener G, Stein DJ. Stress-restress evokes sustained iNOS activity and altered GABA levels and NMDA receptors in rat hippocampus. Psychopharmacology2004b; 175: 494-502.

88. Campbell IK, Roberts LJ, Wicks IP. Molecular targets in immunemediated diseases: the case of tumour necrosis factor and rheumatoid arthritis. Immunol Cell Biol 2003; 81: 354-66.

89. Maes M, Lin AH, Delmeire L, Van Gastel A, et al. Elevated serum interleukin-6 and interleukin-6 receptor concentrations in posttraumatic stress disorder following accidental man-made traumatic events. Biol Psychiatry 1999; 45: 833-839.

90. Baker DG, Ekhator NN, Kasckow JW, et al. Plasma and cerebrospinal fluid interleukin-6 concentrations in posttraumatic stress disorder. Neuroimmunomodulation 2001; 9: 209-217.

91. Harvey BH, Bothma T, Nel A, Wegener G, Stein DJ. Involvement of the NMDA receptor, NO-cyclic GMP and nuclear factor $k-b$ in an animal model of repeated trauma. Human Psychopharmacol 2005b; 20: 367-73.

92. Yeh CB, Leckman JF, Wan FJ, Shiah IS, Lu RB. Characteristics of acute stress symptoms and nitric oxide concentration in young rescue workers in Taiwan. Psychiatry Res 2002;112: 59-68.

93. Heresco-Levy U, Kremer I, Javitt DC, Goichman R et al. Pilotcontrolled trial of D-cycloserine for the treatment of post-traumatic stress disorder. Int J Neuropsychopharmacol 2002;5: 301-7

94. Kessler RC, MCGonagle KC, Zhao S et al. Lifetime and 12-month prevalence of DSM-III-R psychiatric disorders in the United States: Results from the National Comorbidity Survey. Archives of General Psychiatry 1994; 51, 8-19.

95. Murray CJL, Lopez A D. Global Burden of Disease: A Comprehensive Assessment of Mortality and Morbidity from Diseases, Injuries and Risk Factors in 1990 and Projected to 2020, Vol I. Harvard: World Health Organization. Harvard, World Health Organization, 1996.

96. Dupont R L, Rice DP, Miller LS, et al. Economic costs of anxiety disorders. Anxiety 1996; 2, 167-172.

97. Greenberg PE, Sisitsky T, Kessler RC, Finkelstein S, Berndt ER, Davidson JR T, et al. The economic burden of the anxiety disorders in the 1990.s. J Clin Psychiatry 1999; 60, 427-435.

98. Tanno AP, Bianchi FJ, Costa Sampaio Moura MJ, Marcondes FK. Atrial supersensitivity to noradrenaline in stressed female rats. Life Sci 2002; 71: 2973-981.

99. Matsuoka N, Kodama H, Arakawa H, Yamaguchi I. N-Methyl-Daspartate receptor blockade by dizocilpine prevents stress-induced sudden death in cardiomyopathic hamsters. Brain Res 2002 944: 200-4.

100. Stein DJ, Seedat S, Carey P, Harvey BH. Precursors, early detection, and prevention of anxiety disorders. In: M Maj, LopezIbor JJ, Sartorius N, Sato M, Okasha A (eds), Early Detection and Management of Mental Disorders, John Wiley and Sons, Chichester, UK, 2005; pp 231-248. 